\title{
SÍNTESE, CARACTERIZAÇÃO E ANÁLISE TÉRMICA DOS SAIS DE LÍTIO, SÓDIO E POTÁSSIO DO ÁCIDO PALMÍTICO E DO SEU ÉSTER ETÍLICO
}

\author{
André Luis Castro de Sales, Luiz Antônio Ramos, Ronaldo Spezia Nunes, Salvador Claro Neto e Éder Tadeu Gomes \\ Cavalheiro* \\ Instituto de Química de São Carlos, Universidade de São Paulo, CP 780, 13560-970 São Carlos - SP, Brasil
}

Recebido em 17/12/07; aceito em 4/4/08; publicado na web em 17/9/08

\begin{abstract}
SYNTHESIS, CHARACTERIZATION AND THERMAL ANALYSIS OF LITHIUM, SODIUM AND POTASSIUM SALTS OF THE PALMITIC ACID AND ITS ETHYL ESTER. Alkaline salts of the palmitic acid were synthesized and characterized from aqueous and ethanolic medium. The salts were characterized by elemental analysis (EA) and infrared spectroscopy (IR). EA and IR, being its synthesis comproved, also characterized the ethyl palmitate. All the salts and the ester were submitted to thermal analysis using thermogravimetry (TG), and differential thermal analysis (DTA) in the temperature ranging from room to $700{ }^{\circ} \mathrm{C}$ under air dynamic atmosphere. Differential scanning calorimetry (DSC) measurements were taken from $-90{ }^{\circ} \mathrm{C}$ up to temperatures close to the starting of the decomposition temperature, determined by thermogravimetry, using heating and cooling cycles.
\end{abstract}

Keywords: palmitic acid; thermal analysis; thermogravimetry.

\section{INTRODUÇÃO}

O ser humano utiliza óleos e gorduras para diversas finalidades, mesmo antes de descrever suas propriedades químicas e físicas. No passado, os usos mais freqüentes estavam nos lubrificantes para mover objetos pesados como pedras ou esculturas, isolantes térmicos para as estações mais frias do ano, combustível para iluminação ou, ainda, como cosméticos. ${ }^{1}$ Atualmente, o conhecimento da composição química permite melhor domínio de suas propriedades, levando a um vasto número de utilidades para esses materiais, com aplicações nas indústrias de alimentos, lubrificantes e combustíveis com baixo impacto ambiental e toxicidade..$^{1-6}$

Os óleos vegetais são naturalmente constituídos de triglicérides de ácidos graxos. Quimicamente, os ácidos graxos consistem de compostos que apresentam uma cadeia carbônica relativamente longa, contendo em uma extremidade o grupo alquila $-\mathrm{CH}_{3}$ e na outra extremidade o grupo carboxila-COOH. As cadeias podem conter ligações insaturadas e substituintes, geralmente grupos hidroxila $-\mathrm{OH}$, que conferem diferentes propriedades, apesar da semelhança química destes ácidos.

Dentre os diversos ácidos graxos existentes e conhecidos, pode-se destacar o ácido n-hexadecanóico, comercialmente conhecido como ácido palmítico (Hpal). Este ácido pode ser adquirido comercialmente com grau de pureza relativamente alto e sua fórmula estrutural pode ser representada por:

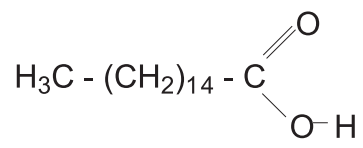

A principal fonte de obtenção do Hpal é o óleo da palma (Elaeis guineensis), o qual contém cerca de $40 \%(\mathrm{~m} / \mathrm{m})$ de Hpal em sua composição. Outras fontes são as gorduras dos peixes ou óleos vegetais extraídos do amendoim, soja, milho, etc. ${ }^{1,7,8}$

Os sais do Hpal são formados pela reação de neutralização deste ácido com uma base. Estes sais, principalmente os de lítio, sódio e

\footnotetext{
*e-mail: cavalheiro@iqsc.usp.br
}

potássio, possuem vasta aplicabilidade como constituintes de tintas, antioxidantes, lubrificantes e isolantes para proteção contra a ação corrosiva da água. ${ }^{4,5}$ As características ou propriedades que mais se destacam para esses sais são seu polimorfismo e a possibilidade de formação de cristal líquido.

Neste trabalho, são descritos estudos sobre a síntese e comportamento térmico de derivados do ácido palmítico. Foram preparados os sais de lítio, sódio e potássio e o éster etílico deste ácido graxo. Os estudos de decomposição térmica foram realizados usando-se termogravimetria (TG), termogravimetria derivada (DTG) e análise térmica diferencial (DTA). Já a calorimetria exploratória diferencial (DSC) foi usada para avaliar o polimorfismo das amostras em baixas temperaturas.

Vale ressaltar que, com o advento dos biocombustíveis, bastante comentados atualmente, tais estudos se tornam importantes, principalmente considerando que estes derivados apresentam transições de fase em temperaturas abaixo da sua decomposição, sendo freqüentemente usados como aditivos de óleos de motores e graxas.

Apesar de já investigados no passado, estudos sistemáticos destes compostos usando técnicas analíticas mais modernas, como o DSC, não são comuns e podem ser ferramentas importantes para o entendimento e direcionamento das aplicações destas substâncias no futuro.

\section{PARTE EXPERIMENTAL}

\section{Reagentes e soluções}

Todos os reagentes utilizados no presente trabalho foram de grau analítico PA ou previamente tratados de acordo com metodologia descrita para cada caso. ${ }^{9}$

Inicialmente, realizou-se uma purificação do Hpal comercial (Vetec, 98\%), adicionando-se o ácido em solução $0,1 \mathrm{~mol} \mathrm{~L}^{-1}$ de $\mathrm{NaOH}$. A solução foi aquecida a $60^{\circ} \mathrm{C}$ e mantida sob agitação até a solubilização completa do ácido. Em seguida, adicionou-se solução $0,1 \mathrm{~mol} \mathrm{~L}^{-1}$ de $\mathrm{HCl}$, gota-a-gota, até pH 3,0. Após 24 h de agitação, nestas condições, o Hpal foi filtrado e lavado com água morna para retirada de possível contaminação de palmitato de sódio. 
A síntese dos sais foi iniciada com a solubilização do Hpal em quantidade adequada de etanol. Em seguida, foi adicionada a base ( $\mathrm{LiOH}, \mathrm{NaOH}$ ou $\mathrm{KOH}$ ) em quantidade estequiométrica. A solução resultante foi mantida sob agitação durante $45 \mathrm{~min}$ a temperatura ambiente. Os sais de lítio e sódio precipitaram espontaneamente, enquanto o sal de potássio foi obtido após evaporação da metade do solvente. Os produtos de reação foram separados por filtração e lavados sucessivamente com éter etílico, etanol e acetona e em seguida foram secos em estufa a $40{ }^{\circ} \mathrm{C}$, sob pressão reduzida.

Na síntese do palmitato de etila, inicialmente solubilizou-se o Hpal em etanol na proporção 1:4 de Hpal/etanol (m/v). Adicionou-se solução $0,5 \mathrm{~mol} \mathrm{~L}^{-1}$ de $\mathrm{H}_{2} \mathrm{SO}_{4}$ até uma concentração de $0,5 \%(\mathrm{~m} /$ v) do ácido e a mistura foi colocada em sistema de refluxo durante $2 \mathrm{~h}$. O produto foi filtrado e lavado com solução de hidrogeno carbonato de sódio $5 \%(\mathrm{~m} / \mathrm{v})$ para a remoção do Hpal que não reagiu, seguida de uma segunda lavagem com água morna para a eliminação de resíduos de hidrogeno carbonato de sódio.

\section{Instrumentação e procedimentos}

Os espectros na região do infravermelho foram obtidos em um espectrofotômetro Nicolet 5 SXC e os resultados de análise elementar em analisador elementar EA 1110 CNHS-O da CE Instruments.

As curvas TG/DTG foram obtidas em um analisador térmico simultâneo TG-DTA SDT Q600, e as curvas DSC foram obtidas em um calorímetro DSC Q10, controlados pelo Software Thermal Advantage for $Q$ Series (v.4.2.1) da TA Instruments.

Todos os experimentos de termogravimetria e termogravimetria derivada (TG/DTG) foram realizados com razão de aquecimento de $10{ }^{\circ} \mathrm{C} \mathrm{min}^{-1}$, entre temperatura ambiente e $700{ }^{\circ} \mathrm{C}$, em atmosfera dinâmica de ar com vazão de $100 \mathrm{~mL} \mathrm{~min}^{-1}$, massa de amostra em torno de $3 \mathrm{mg}$, utilizando suporte de amostra aberto de alumina.

Os experimentos de DSC foram realizados em ciclos de aquecimentos e resfriamento entre -90 e $170{ }^{\circ} \mathrm{C}$ para verificar a presença de eventos térmicos em temperatura sub-ambiente, utilizando razão

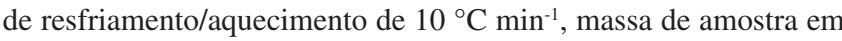
torno de $2 \mathrm{mg}$, vazão de gás de $50 \mathrm{~mL} \mathrm{~min}^{-1}$ de $\mathrm{N}_{2}$.

Inicialmente a amostra foi resfriada até $-90^{\circ} \mathrm{C}$, sendo mantida nesta temperatura por 3 min para estabilização térmica. A seguir a amostra foi aquecida de -90 até $170{ }^{\circ} \mathrm{C}$, seguida de isoterma por 3 min na temperatura final, e resfriada até $-90{ }^{\circ} \mathrm{C}$, encerrando-se o ciclo de resfriamento/aquecimento. Esta programação foi repetida para os demais ciclos.

\section{RESULTADOS E DISCUSSÃO}

\section{Caracterização dos sais e do éster obtidos a partir do ácido palmítico}

Os resultados de análise elementar dos sais e do éster preparados neste trabalho são apresentados na Tabela 1 e sugerem que os compostos foram obtidos com sucesso, considerando-se a presença de resíduos de etanol, no caso do sal de sódio.

\section{Espectroscopia vibracional na região do infravermelho}

Os espectros do Hpal, dos sais e do éster são apresentados na forma de material suplementar. $\mathrm{O}$ espectro de absorção na região do infravermelho do Hpal permite observar a presença de uma banda larga entre 3300 e $2500 \mathrm{~cm}^{-1}$ referente a estiramento axial da hidroxila, presente na carboxila terminal. Três bandas centradas em
Tabela 1. Resultados de análise elementar dos compostos sintetizados

\begin{tabular}{lcc}
\hline Composto & \multicolumn{2}{c}{ Calc $($ Exp) /\% } \\
\hline Hpal & $74,9(74,8)$ & H \\
\hline Em etanol & & \\
Lipal & $73,3(71,6)$ & $11,8(11,9)$ \\
Napal & $69,0(67,9)$ & $11,1(11,7)$ \\
Kpal & $65,2(65,4)$ & $10,5(10,8)$ \\
Éster & $76,0(75,5)$ & $12,6(11,9)$ \\
\hline
\end{tabular}

$2915 \mathrm{~cm}^{-1}$ referentes ao estiramento axial de $\mathrm{C}-\mathrm{H}$ podem ser vistas. A banda característica de estiramento axial de $\mathrm{C}=\mathrm{O}$ apresenta-se em $1690 \mathrm{~cm}^{-1}$. Finalmente surge a banda em $1290 \mathrm{~cm}^{-1}$, referente ao estiramento axial de $\mathrm{C}-\mathrm{O}-\mathrm{H} .{ }^{10}$

Os espectros de absorção na região do infravermelho dos sais, Lipal, Napal e Kpal apresentaram as bandas características de estiramento axial de C-H em 2915, 2928 e $2922 \mathrm{~cm}^{-1}$, estiramento axial de $\mathrm{C}=\mathrm{O}$ em torno de 1573,1550 e $1414 \mathrm{~cm}^{-1}$, respectivamente.

O Lipal apresenta bandas de deformação angular simétrica de $\mathrm{CH}_{2}$ em 1556, 1450 e $1397 \mathrm{~cm}^{-1}$ e, por fim, deformação angular assimétrica em $730 \mathrm{~cm}^{-1}$. O Napal apresenta deformação angular de $\mathrm{CH}_{2}$ simétrico, em $1438 \mathrm{~cm}^{-1}$, e outro assimétrico em $722 \mathrm{~cm}^{-1}$, enquanto o $\mathrm{Kpal}$, em $1414 \mathrm{~cm}^{-1}$ a deformação angular simétrica de $\mathrm{CH}_{2}$ e, em 716 $\mathrm{cm}^{-1}$ a deformação angular assimétrica de $\mathrm{CH}_{2} \cdot{ }^{10} \mathrm{Como}$ conseqüência da formação dos sais, observou-se um deslocamento da banda da carbonila para menor número de onda em todos os casos.

O espectro do palmitato de etila apresenta a banda de estiramento axial de C-H em $2915 \mathrm{~cm}^{-1}$. Além disso, pode-se observar também uma banda em $1740 \mathrm{~cm}^{-1}$ referente a estiramento axial de $\mathrm{C}=\mathrm{O}$. Apresentam-se também duas bandas: uma em $1184 \mathrm{~cm}^{-1}$ referente a estiramento axial de $\mathrm{C}-\mathrm{C}(=\mathrm{O})-\mathrm{O}$ e a outra, referente ao estiramento axial de $\mathrm{O}-\mathrm{C}-\mathrm{C}$, em $1031 \mathrm{~cm}^{-1}$. O estiramento axial de $\mathrm{C}=\mathrm{O}$ ocorre em número de onda mais alto, pois a constante de força da ligação carbonila é aumentada pela tendência do átomo de oxigênio adjacente atrair elétrons (efeito indutivo). ${ }^{10}$

\section{Termogravimetria e termogravimetria derivada (TG/DTG)}

As curvas TG/DTG para todos os compostos investigados neste trabalho estão reunidas na Figura 1.

No caso do Hpal (Figura 1a), observa-se uma única perda de massa entre 116,3 e $550,8^{\circ} \mathrm{C}$, com perda de $97,1 \%$ e resíduo de $2,9 \%$ no suporte de amostra a $650{ }^{\circ} \mathrm{C}$. O resíduo observado foi atribuído à presença de material carbonizado e/ou restos de compostos inorgânicos não eliminados na purificação efetuada.

Para o Lipal (Figura 1b), pode-se observar que a decomposição ocorre por processos complexos, que se iniciam próximo a $192,0{ }^{\circ} \mathrm{C}$ e terminam em $534,0^{\circ} \mathrm{C}$, após queima abrupta da matéria orgânica. O resíduo a $542,5{ }^{\circ} \mathrm{C}$ foi atribuído ao $\mathrm{Li}_{2} \mathrm{CO}_{3}$ (TG: $14,9 \%$; calc.: $14,1 \%$ ), o que foi comprovado com espectros IV.

A curva TG/DTG do Napal (Figura 1c) apresenta a perda de resíduos de etanol, desde o início do experimento até $105,8{ }^{\circ} \mathrm{C}$, correspondendo à perda de $0,10 \mathrm{~mol}$ de $\mathrm{EtOH}$ por mol de composto. A quantidade não estequiométrica foi atribuída a uma perda incompleta de solvente durante o processo de secagem do sal. $\mathrm{Na}$ sequiência surge a decomposição do sal, representada por várias etapas sucessivas entre 172,5 e $480,0{ }^{\circ} \mathrm{C}$, com perda de $74,1 \%$ da massa inicial. Essa perda pode ser considerada em duas regiões, a decomposição propriamente dita entre 172,5 e $414,6{ }^{\circ} \mathrm{C}$ (TG: $29,3 \%$ ) e a queima abrupta de material carbonizado entre 414,6 e $480,0{ }^{\circ} \mathrm{C}$ (TG: $44,7 \%$ ). O produto de decomposição a $550,8{ }^{\circ} \mathrm{C}$ foi caracterizado como sendo o carbonato de sódio, por meio de seu 


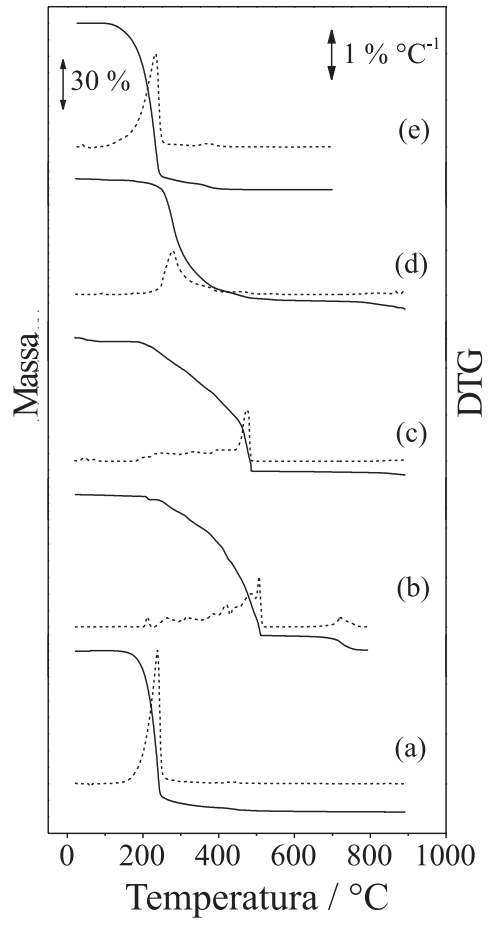

Figura 1. Curvas TG/DTG obtidas em razão de aquecimento de $10^{\circ} \mathrm{C} \mathrm{min}{ }^{-1}$,

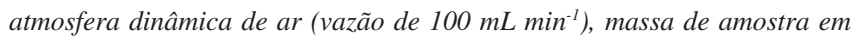
torno de $3 \mathrm{mg}$, utilizando suporte de amostra aberto de alumina. (a) Hpal, (b) Lipal, (c) Napal, (d) Kpal e (e) Etilpal

espectro IV (TG: 19,1\%; calc: 19,0\%).

O perfil termogravimétrico do Kpal (Figura 1d) apresenta uma perda em $53,1^{\circ} \mathrm{C}$ que pode estar relacionada com a perda de umidade ou solvente residual, correspondente a $0,3 \%$ da massa inicial. Uma segunda perda de massa inicia-se em $172,7^{\circ} \mathrm{C}$ e se estende até $650,0^{\circ} \mathrm{C}$, referente à decomposição do composto. $\mathrm{O}$ resíduo gerado pela decomposição do Kpal foi caracterizado como carbonato de potássio, segundo seu espectro IV (TG: $25,8 \%$; calc.: $24,3 \%$ ).

O palmitato de etila (Figura 1e) apresentou decomposição em uma etapa entre 94,3 e $445,8^{\circ} \mathrm{C}$, com perda integral de massa. Observa-se que neste intervalo de temperatura houve formação de material carbonizado, que queima entre 302,0 e $451,7^{\circ} \mathrm{C}$, não havendo definição entre final da decomposição e o início da queima do material carbonizado.

\section{Análise térmica diferencial (DTA)}

As curvas DTA para todos os compostos são apresentadas na Figura 2.

A curva DTA do Hpal (Figura 2a) revelou um pico endotérmico atribuído à fusão em $61,6^{\circ} \mathrm{C}\left(T_{\text {onset }}=59,5^{\circ} \mathrm{C}\right)$. O pico de fusão encontrado para o ácido concorda com o relatado na literatura, ${ }^{1,7}$ entre $62-64{ }^{\circ} \mathrm{C}$. O ponto de fusão também foi determinado usando um tubo capilar, com o qual chegou-se a $62,3{ }^{\circ} \mathrm{C}$ para este evento. Seguem-se picos exotérmicos em $252,2,363,5$ e $470,7{ }^{\circ} \mathrm{C}$, todos relativos à decomposição.

Para o Lipal, os resultados de DTA (Figura 2b) corroboram com as curvas TG/DTG, quanto à complexidade em relação ao número de eventos presentes. Observa-se em $108,0{ }^{\circ} \mathrm{C}$ pico endotérmico referente à conversão da forma Lipal-I para a forma Lipal-II, que é uma fase totalmente cristalina segundo Vold et al.. ${ }^{11,12}$ Estes mesmos autores atribuíram o pico exotérmico em $213,1{ }^{\circ} \mathrm{C}$ à conversão da forma Lipal-II a Lipal-III, uma mesofase de cristal líquido, que não seria convertida a nenhuma das formas anteriores, por resfriamento.

Vold et al. não comentam, mas o presente trabalho mostra que, acima de $215,0{ }^{\circ} \mathrm{C}$ ocorre perda de massa. A decomposição, ainda que parcial, poderia explicar porque a fase de partida não pode ser obtida por resfriamento do Lipal-III.

Podem-se observar diversos picos endotérmicos e exotérmicos entre o início do experimento e $400{ }^{\circ} \mathrm{C}$ nas curvas DTA do Napal (Figura 2c), relativos a mudanças de fase e decomposição, de acordo com as curvas TG/DTG. A literatura afirma que a fusão do sal ocorre em $295,0^{\circ} \mathrm{C},{ }^{13-16}$ porém nesta temperatura já ocorre perda de massa, tornando duvidosa esta afirmação, a qual só poderia ser verídica se ocorresse fusão associada à decomposição. Isto parece ser o que realmente ocorre segundo observações em tubo capilar. Acima de $400^{\circ} \mathrm{C}$ observa-se processo exotérmico intenso relativo à queima de material orgânico, com pico em $484,4^{\circ} \mathrm{C}$.

No caso do Kpal (Figura 2d), foram observados picos endotérmicos e exotérmicos conforme se descreve a seguir. O pico endotérmico em $72,4^{\circ} \mathrm{C}$ pode ser atribuído à mudança de fase e acima de 280,5 ${ }^{\circ} \mathrm{C}$ pode-se observar o pico exotérmico referente à decomposição. Segundo a literatura, ${ }^{17-19}$ a fusão do Kpal acontece em $375,0{ }^{\circ} \mathrm{C}$, porém nesta temperatura já ocorre perda significativa de massa, evidenciando a decomposição do sal e colocando em dúvida se realmente ocorre fusão.

A curva DTA do palmitato de etila (Figura 2e) sugere que, antes da decomposição, ocorram eventos físicos com picos endotérmicos em 44,2 e 70,2 ${ }^{\circ} \mathrm{C}$, provavelmente referentes à fusão e transições de fase, como será discutido adiante juntamente com as curvas DSC. Já a decomposição ocorre por processos exotérmicos com picos em 202,3; 253,3; 289,4 e $381,3^{\circ} \mathrm{C}$, em concordância com os resultados de TG/DTG.

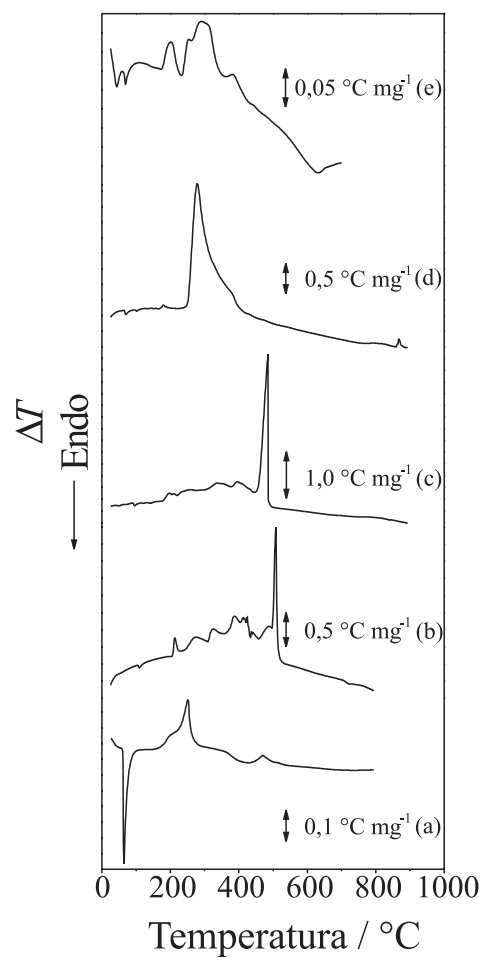

Figura 2. Curvas DTA obtidas em razão de aquecimento de $10{ }^{\circ} \mathrm{C} \mathrm{min}{ }^{-1}$,

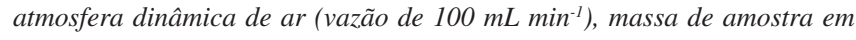
torno de $3 \mathrm{mg}$, utilizando suporte de amostra aberto de alumina. (a) Hpal, (b) Lipal, (c) Napal, (d) Kpal e (e) Etilpal 


\section{Calorimetria exploratória diferencial (DSC)}

É importante ressaltar que não foram encontrados estudos sistemáticos de DSC para estes compostos, previamente apresentados na literatura. As observações prévias foram feitas usando-se DTA e estudos de aquecimento de amostras e observação direta dos eventos. A metodologia adotada neste trabalho foi a de ciclos sucessivos de resfriamento/aquecimento, para observar transições de fase antes das decomposições.

No caso do Hpal, não se observa nenhum evento térmico na curva DSC (ver material suplementar), referente ao resfriamento da temperatura ambiente até $-90,0^{\circ} \mathrm{C}$. No $2^{\circ}$ e $4^{\circ}$ ciclos, observou-se a fusão do Hpal com pico em $63,7^{\circ} \mathrm{C}\left(T_{\text {onset }}=61,7^{\circ} \mathrm{C}\right)$. A entalpia de fusão registrada foi de $194,8 \mathrm{~J} \mathrm{~g}^{-1}$. Já no $3^{\circ}$ e $5^{\circ}$ ciclos, observou-se a cristalização do ácido palmítico com pico exotérmico em $57,0^{\circ} \mathrm{C}$ $\left(T_{\text {onset }}=56,7^{\circ} \mathrm{C}\right.$ ), com entalpia de cristalização de $191,7 \mathrm{~J} \mathrm{~g}^{-1}$. Os ciclos de aquecimento/resfriamento, nesta faixa de temperatura, apresentam a fusão/cristalização como único evento térmico.

O comportamento do Lipal, de acordo com as curvas DSC (ver material suplementar) entre -90 e $170{ }^{\circ} \mathrm{C}$ mostrou que não houve mudanças de fase abaixo de $90{ }^{\circ} \mathrm{C}$. Em concordância com Vold et $a l .{ }^{11,12}$ observou-se uma transição reversível de Lipal-I para Lipal-II com pico em $109,2^{\circ} \mathrm{C}\left(T_{\text {onset }}=106,7^{\circ} \mathrm{Ce} \Delta H=43,9 \mathrm{~J} \mathrm{~g}^{-1}\right)$. Já no ciclo de resfriamento observou-se a cristalização representada por um pico exotérmico em $101,0{ }^{\circ} \mathrm{C}\left(T_{\text {onset }}=103,6{ }^{\circ} \mathrm{C}\right.$ e $\left.\Delta H=42,8 \mathrm{~J} \mathrm{~g}^{-1}\right)$. Este evento foi o único pico observado neste intervalo de temperatura.

Nos ciclos de aquecimento/resfriamento realizados para o Napal (Figura 3), o resfriamento inicial até $-90^{\circ} \mathrm{C}$ não apresentou nenhum evento térmico. Ao aquecer a amostra a $10{ }^{\circ} \mathrm{C} \mathrm{min}{ }^{-1}$ entre -90 e 170 ${ }^{\circ} \mathrm{C}$, temperatura na qual a curva TG sugere início de perda de massa, observou-se a saída de etanol com pico endotérmico em $67,0^{\circ} \mathrm{C}$. Após este evento, surgiram três picos endotérmicos, provavelmente relativos a mudanças de fase, com máximos em $94,0,122,1$ e $144,1^{\circ} \mathrm{C}$.

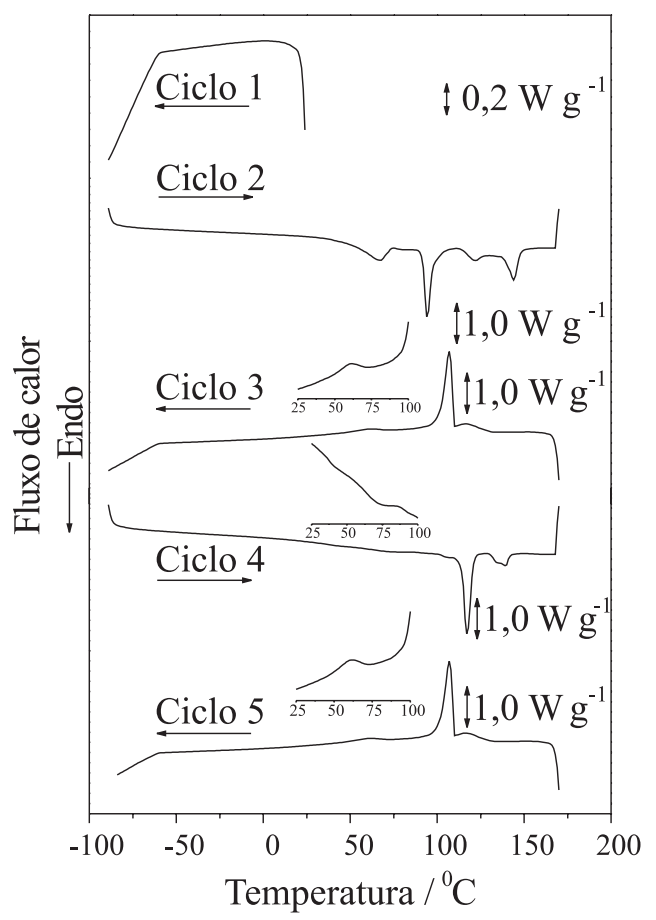

Figura 3. Curvas DSC do Napal, realizadas em ciclos de aquecimento/ resfriamento entre -90 e $170{ }^{\circ} \mathrm{C}$ com razão de resfriamento/aquecimento de $10{ }^{\circ} \mathrm{C} \mathrm{min}^{-1}$, massa de amostra de $2 \mathrm{mg}$, atmosfera dinâmica de $\mathrm{N}_{2}$ (vazão de

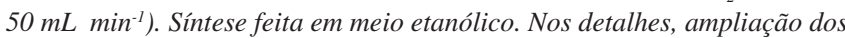
eventos observados em torno de $70^{\circ} \mathrm{C}$
A amostra foi então novamente resfriada a $10{ }^{\circ} \mathrm{C} \mathrm{min}{ }^{-1}$ (ciclo 3 ), apresentando processos exotérmicos de mudanças de fase com picos em 116,4 e $107,2{ }^{\circ} \mathrm{C}$, seguidos de um processo exotérmico representado por um pico de aspecto alargado centrado em $62,4^{\circ} \mathrm{C}$, sugerindo que, após a saída do etanol, o comportamento do Napal muda, não sendo reversíveis os processos observados no ciclo 2 .

Ao aquecer novamente a amostra (ciclo 4), nota-se a presença de processos endotérmicos com picos em 73,0, 117,5 e $139,9^{\circ} \mathrm{C}$, referentes a processos de mudança de fase.

A literatura descreve estados físicos para o Napal anidro, segundo os quais há uma controvérsia em relação ao processo em torno de $70^{\circ} \mathrm{C}$.

Vold et al..$^{13,20,21}$ não reconheceram a existência deste evento, de acordo com dados de dilatometria, afirmando que o mesmo se refere a uma mudança na rede cristalina do sal. Já Chesley ${ }^{16}$ reconheceu a presença deste evento usando difração de raios X e o atribuiu a uma mudança de aglomerados fibrosos na forma I para a forma II. O autor afirmou ainda que, por se tratar de uma mudança muito sutil no volume da amostra, não seria possível constatar esta mudança de fase por dilatometria.

Ambos os autores concordam com a conversão a uma fase chamada sub-cerosa, (subwaxy) com pico em $117^{\circ} \mathrm{C}$ para uma fase "cerosa" em $140{ }^{\circ} \mathrm{C}$. Acima disto, Chesley ${ }^{16}$ e Vold et al. ${ }^{13,15,20}$ descrevem as fases sub-líquida, a partir de $205^{\circ} \mathrm{C}$, e líquida a $257^{\circ} \mathrm{C}$. Em seguida observa-se a presença de uma fase líquida isotrópica em $290{ }^{\circ} \mathrm{C}$, o que pode ser visto na curva DTA (Figura 2c). Entretanto, a curva TG mostra decomposição com perda de massa desde $175,7^{\circ} \mathrm{C}$, e estas fases poderiam ser produtos de decomposição.

Uma das principais contribuições do presente trabalho é confirmar a transição da fase de aglomerados fibrosos $I$ para a forma $I I$, observada por Chesley, ${ }^{16}$ a qual é representada por picos muito sutis no DSC, em torno de $70^{\circ} \mathrm{C}$, sendo mais pronunciado no resfriamento que no aquecimento. Os detalhes apresentados na Figura 3, nesta região de temperatura, mostram com maior clareza a presença destes eventos e sugerem sua reversibilidade.

Vold et al. ${ }^{13,15,20}$ contestaram em vários artigos a existência desta transição, inclusive com base em dados de DTA. ${ }^{13}$ Entretanto, esta técnica é menos sensível que o DSC e a transição poderia não ser detectada, como no caso da dilatometria. A Figura $2 \mathrm{c}$ mostra que esta transição não é clara no DTA.

Quando o Napal, obtido em água, é submetido aos ciclos de aquecimento e resfriamento observa-se que já no $1^{\circ}$ resfriamento surge um pico exotérmico de cristalização de água absorvida em $-21,3^{\circ} \mathrm{C}\left(T_{\text {onset }}\right.$ $=-20,8^{\circ} \mathrm{C}$ e $\Delta H=134,4 \mathrm{~J} \mathrm{~g}^{-1}$ ) (ver material suplementar).

Ao aquecer esta amostra surge um pico endotérmico de fusão de água $\left(3,4^{\circ} \mathrm{C}\right)$, que se volatiliza em $94,4^{\circ} \mathrm{C}$. Os demais eventos são semelhantes aos descritos anteriormente para o sal obtido em etanol, com pequenas diferenças, uma vez que a saída da água muda o perfil da curva DSC.

$\mathrm{O}$ terceiro e quarto ciclos também repetem as observações anteriores, inclusive com a conversão dos aglomerados fibrosos de Chesley, ${ }^{16}$ que podem ser observados como um processo endotérmico alargado no quarto ciclo.

As curvas DSC do palmitato de potássio (ver material suplementar) foram realizadas com ciclos de aquecimento e resfriamento com razão de $10{ }^{\circ} \mathrm{C} \min ^{-1}$ no intervalo de temperatura de -90 a $170{ }^{\circ} \mathrm{C}$, no qual ainda não ocorre a decomposição do sal, como sugerem as curvas TG/DTG.

No ciclo 1, observa-se um pico exotérmico em $-38,4{ }^{\circ} \mathrm{C}$, de baixa intensidade, que foi atribuído à presença da umidade ou solvente residual, comentada no TG. No ciclo 2 , observam-se quatro picos endotérmicos, sendo que o primeiro pico em $67,7^{\circ} \mathrm{C}\left(T_{\text {onset }}=63,5^{\circ} \mathrm{Ce} \Delta H=45,9 \mathrm{~J} \mathrm{~g}^{-1}\right)$, segundo Vold et al, ${ }^{19}$ é referente à mudança de fase inter-cristalina do sal. $\mathrm{O}$ segundo pico em $103,3^{\circ} \mathrm{C}\left(T_{\text {onset }}=101,6^{\circ} \mathrm{Ce} \Delta H=2,8 \mathrm{~J} \mathrm{~g}^{-1}\right)$ pode ser atribuído à perda de umidade ou solvente residual. $\mathrm{O}$ terceiro e quarto picos em 133,0 e $148,2^{\circ} \mathrm{C}$ respectivamente $\left(1^{\circ} T_{\text {onset }}=131,6^{\circ} \mathrm{Ce} \Delta H=4,8\right.$ $\left.\mathrm{J} \mathrm{g}^{-1} ; 2^{\circ} T_{\text {onset }}=144,7^{\circ} \mathrm{Ce} \Delta H=7,1 \mathrm{~J} \mathrm{~g}^{-1}\right)$, também segundo Vold et al..$^{19}$ 
são referentes ao que chamaram de grupo ceroso (waxy group). $\mathrm{O} 3^{\circ}$ ciclo, de resfriamento, não apresenta mais o pico em $-38,4^{\circ} \mathrm{C}$, confirmando que, após aquecimento, a umidade ou solvente residual foi eliminado. Os demais ciclos são todos idênticos indicando que as mudanças de fase são reversíveis entre si, reproduzindo-se nos demais ciclos.

As curvas DSC do palmitato de etila (Figura 4) foram obtidas na forma de ciclos de aquecimento/resfriamento entre -90 e $80^{\circ} \mathrm{C}$, utilizando razões de aquecimento de 5,10 e $20^{\circ} \mathrm{C} \mathrm{min}^{-1}$, para avaliar a presença de eventos sobrepostos, pois não há descrição prévia do comportamento térmico deste éster na literatura e este pode vir a ser usado, futuramente, na preparação de biocombustíveis.

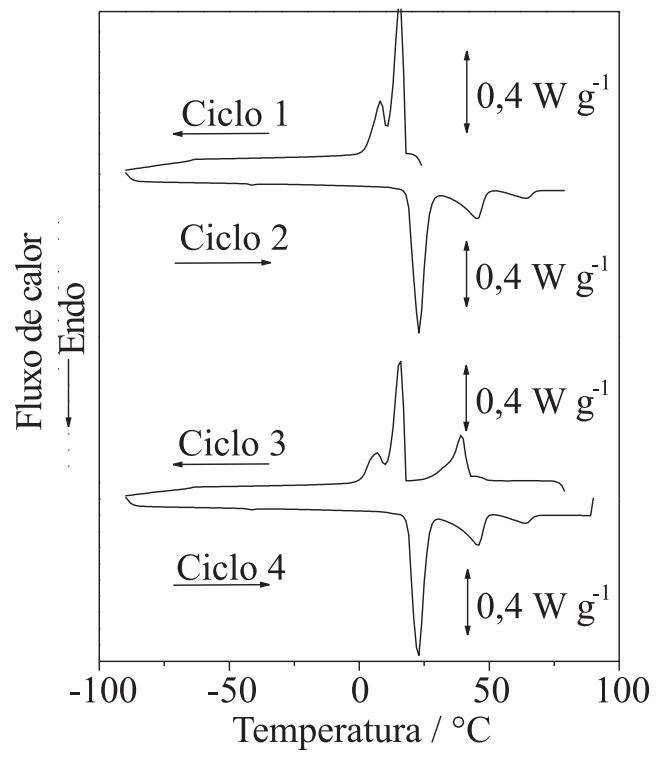

Figura 4. Curva DSC do palmitato de etila realizada em ciclos de aquecimento/resfriamento entre -90 e $170{ }^{\circ} \mathrm{C}$, com razão de resfriamento/aquecimento de $10^{\circ} \mathrm{C} \mathrm{min}^{-1}$, massa de amostra de $2 \mathrm{mg}$, atmosfera dinâmica de $\mathrm{N}_{2}$ (vazão de $\left.50 \mathrm{~mL} \mathrm{~min}^{-1}\right)$.

Entretanto, houve apenas mudança na intensidade dos picos e deslocamento em alguns deles, sem alterações significativas nos perfis calorimétricos. Deslocamentos nas temperaturas de pico sugerem eventos com controle cinético, enquanto aqueles que não se deslocam são considerados como controlados termodinamicamente. ${ }^{22}$ As temperaturas e energias relatadas a seguir relacionam-se às curvas DSC obtidas a $10{ }^{\circ} \mathrm{C} \mathrm{min}^{-1}$.

O pico exotérmico em $15,6^{\circ} \mathrm{C}\left(T_{\text {onset }}=17,8^{\circ} \mathrm{C}\right)$ observado no $1^{\circ}$ ciclo foi relacionado com a solidificação do éster, em uma forma $I$, pois não se deslocou com a variação na razão de aquecimento. Seguese um rearranjo estrutural para a forma $I I \mathrm{com}$ pico em $8,3^{\circ} \mathrm{C}$, o qual se desloca com a alteração da razão de aquecimento.

No $2^{\circ}$ ciclo, observa-se a transformação da forma II com pico endotérmico em $23,2^{\circ} \mathrm{C}\left(T_{\text {onset }}=18,6^{\circ} \mathrm{Ce} \Delta H=106,3 \mathrm{~J} \mathrm{~g}^{-1}\right)$. Esta forma apresenta a seguir, dois processos endotérmicos em 45,3 e $64,3{ }^{\circ} \mathrm{C}$.

O terceiro ciclo mostrou que há uma conversão de fase com pico exotérmico em $39,1^{\circ} \mathrm{C}$ seguida da cristalização na forma $I$ em 15,6 ${ }^{\circ} \mathrm{C}$ e da conversão à forma $I I$ em $8,0^{\circ} \mathrm{C}$.

Uma melhor caracterização destas fases poderia ser realizada por meio de difração de raios X, associada à temperatura e/ou DSC foto-visual, dos quais não dispomos em nosso laboratório.

\section{CONCLUSÃO}

As curvas TG/DTG sugerem que as decomposições dos sais de palmitato ocorrem por processos complexos, resultando nos respectivos carbonatos. As decomposições dos sais ocorrem acima de 170 ${ }^{\circ} \mathrm{C}$, segundo a ordem de estabilidade: Lipal $>$ Napal $\approx \mathrm{Kpal}$.

Os resultados das curvas DSC obtidos para estes compostos revelaram que os mesmos apresentam diversas fases polimórficas precedendo a decomposição. Os estudos realizados anteriormente a este trabalho são conflitantes no que se refere à presença dos aglomerados fibrosos no Napal, os quais foram evidenciados nas curvas DSC.

Também foi possível observar que o processo de fusão do Napal ocorre associado à sua decomposição. Além disto, observou-se a presença de várias fases, também no caso do éster Etilpal.

\section{MATERIAL SUPLEMENTAR}

No material suplementar, são apresentados os espectros de absorção na região do IV para o Hpal, seus sais de $\mathrm{Li}^{+}, \mathrm{Na}^{+}$e $\mathrm{K}^{+}$e para o éster etílico (Figura 1S). Também são apresentadas as curvas DSC do Hpal e dos palmitatos de lítio, sódio (obtido em meio aquoso) e potássio, nas Figuras $2 \mathrm{~S}, 3 \mathrm{~S}, 4 \mathrm{~S}$ e $5 \mathrm{~S}$, respectivamente.

Está disponível gratuitamente em http://quimicanova.sbq.org.br, na forma de arquivo PDF.

\section{AGRADECIMENTOS}

À FAPESP pelo apoio financeiro (processo 06/06633-1), à CAPES e ao CNPq pelas bolsas de estudo.

\section{REFERÊNCIAS}

1. Markley, K. S.; Fatty acids, $2^{\text {nd }}$ ed., Wiley: New York, 1960.

2. Morrison, R. T.; Boyd, R. N.; Química orgânica, Fundação Calouste Gulbenkian: Lisboa, 1961.

3. Allinger, N. L.; Cava, M. P.; Jongh, D. C.; Johnson, C. R.; Lebel, N. A.; Stevens, C. L.; Química Orgânica, $2^{\text {a }}$ ed., Guanabara Dois: Rio de Janeiro, 1978.

4. Sari, A.; Appl. Therm. Eng. 2005, 25, 2100.

5. Zhanga, J. J.; Zhangb, J. L.; Hea, S. H.; Wuc, K.; Liu, X.; Thermochim. Acta 2001, 369, 157.

6. Tuncbilek, K.; Sari, A.; Tarhan, S.; Ergünes, G.; Kaygusuz, K.; Energy 2005, 30, 677.

7. The Merck Index, Budavai, S., ed.; $12^{\text {th }}$ ed., Merck: White House Station, 1996.

8. Hua, K.; Hsu, H.; Su, Y.; Lin, I.; Yang, S.; Chen, Y.; Chao, L. K.; J. Agric. Food Chem. 2005, 54, 306.

9. Perrin, D. D.; Purification of laboratory chemicals, $2^{\text {nd }}$ ed., Pergamon Press: New York, 1980.

10. Silverstein, R.M.; Identificação espectrométrica de compostos orgânicos, $3^{\text {rd }}$ ed., Guanabara: Rio de Janeiro, 1979.

11. Vold, M. J.; Funakoshi, H.; Vold, R. D.; J. Phys. Chem. 1976, 80, 1753.

12. Vold, M. J.; J. Am. Chem. Soc. 1943, 65, 465.

13. Vold, R. D.; J. Am. Chem. Soc. 1941, 63, 2915.

14. Nordsiek, H.; Rosevear, F. B.; Ferguson, R. H.; J. Chem. Phys. 1948, 16, 175.

15. Vold. M. J.; J. Am. Chem. Soc. 1941, 63, 160.

16. Chesley, F. G.; J. Chem. Phys. 1940, 8, 643.

17. Hieke, A.; Dörfler, H. -D.; Colloid Polym. Sci. 1999, 277, 762.

18. Dorfler, H. -D.; Fett Wissenschaft Technologie-Fat Science Technology 1994, 96, 371.

19. Vold, R. D.; Vold, M. J.; J. Phys. Chem. 1945, 49, 32.

20. Vold, R. D.; Vold, M. J.; J. Am. Chem. Soc. 1939, 61, 808.

21. Vold, M. J.; Macomber, M.; Vold, R. D.; J. Am. Chem. Soc. 1941, 63, 168.

22. Wendlandt, W.W.; Thermal analysis, $3^{\text {rd }}$ ed., Wiley: New York, 1986. 


\section{SÍNTESE, CARACTERIZAÇÃO E ANÁLISE TÉRMICA DOS SAIS DE LÍTIO, SÓDIO E POTÁSSIO DO ÁCIDO PALMÍTICO E DO SEU ÉSTER ETÍLICO}

André Luis Castro de Sales, Luiz Antônio Ramos, Ronaldo Spezia Nunes, Salvador Claro Neto e Éder Tadeu Gomes Cavalheiro*

Instituto de Química de São Carlos, Universidade de São Paulo, CP 780, 13560-970 São Carlos - SP, Brasil

Neste material suplementar, são apresentados os espectros de absorção na região do IV para o Hpal, seus sais de $\mathrm{Li}^{+}, \mathrm{Na}^{+} \mathrm{e}$ $\mathrm{K}^{+}$e para o éster etílico (Figura 1S). Também são apresentadas as curvas DSC do Hpal e dos palmitatos de lítio, sódio (obtido em meio aquoso) e potássio, nas Figuras $2 \mathrm{~S}, 3 \mathrm{~S}, 4 \mathrm{~S}$ e $5 \mathrm{~S}$, respectivamente.

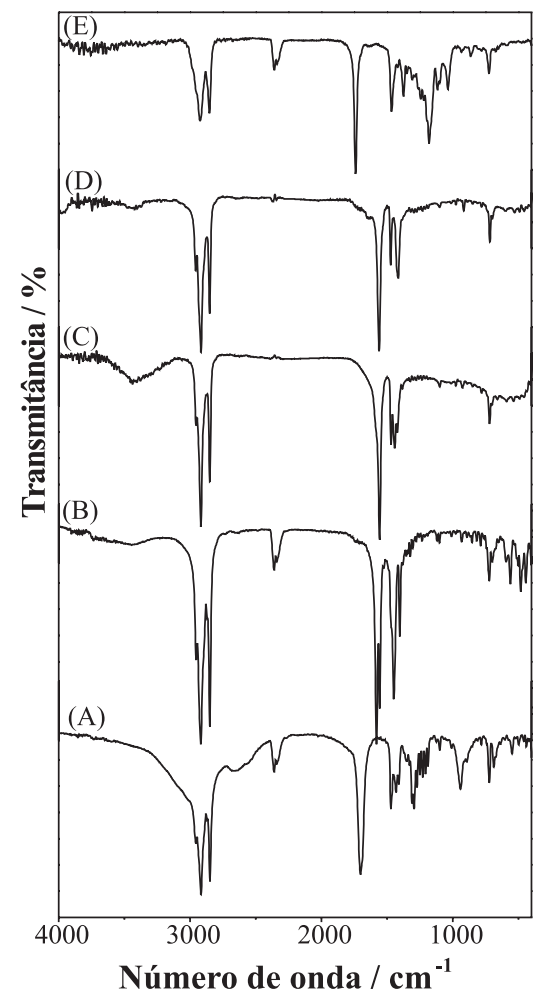

Figura 1S. Espectros de absorção na região do infravermelho dos compostos, obtidos em pastilhas de KBr. (a) Hpal, (b) Lipal, (c) Napal, (d) Kpal e (e) Etilpal 


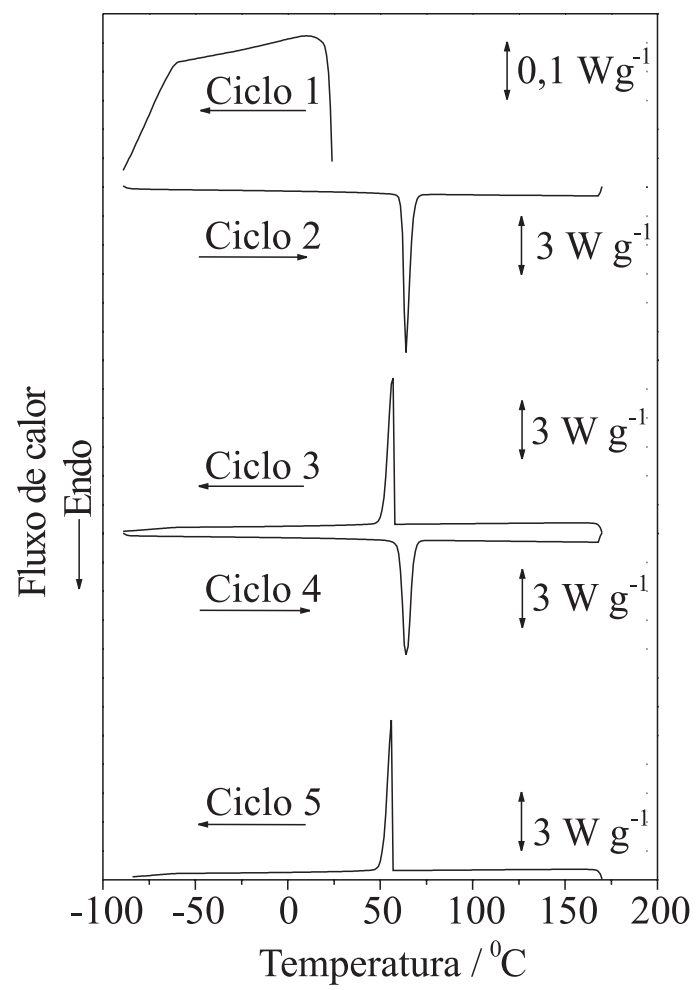

Figura 2S. Curvas DSC do Hpal realizadas em ciclos de aquecimento/resfriamento entre -90 e $170{ }^{\circ} \mathrm{C}$ com razão de resfriamento/aquecimento de $10^{\circ} \mathrm{C}$ min ${ }^{-1}$, massa de amostra de $2 \mathrm{mg}$, atmosfera dinâmica de $\mathrm{N}_{2}$ (vazão de $50 \mathrm{~mL} \mathrm{~min}{ }^{-1}$ )

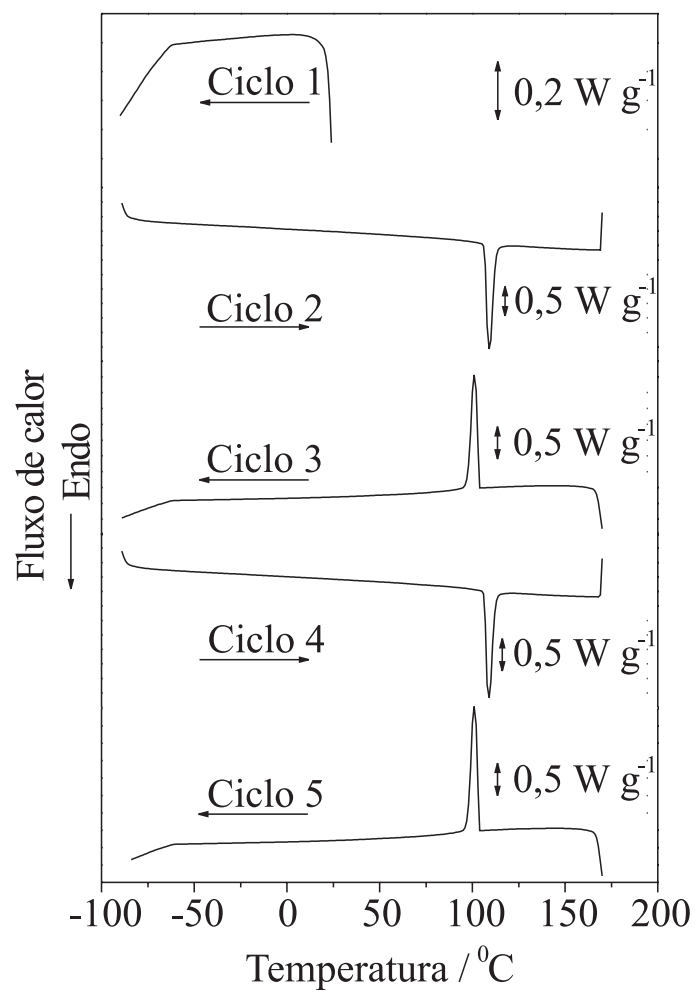

Figura 3S. Curvas DSC do Lipal realizadas em ciclos de aquecimento/resfriamento entre -90 e $170{ }^{\circ} \mathrm{C}$ com razão de resfriamento/aquecimento de $10^{\circ} \mathrm{C}$ min ${ }^{-1}$, massa de amostra de $2 \mathrm{mg}$, atmosfera dinâmica de $\mathrm{N}_{2}$ (vazão de $50 \mathrm{~mL} \mathrm{~min}^{-1}$ ) 


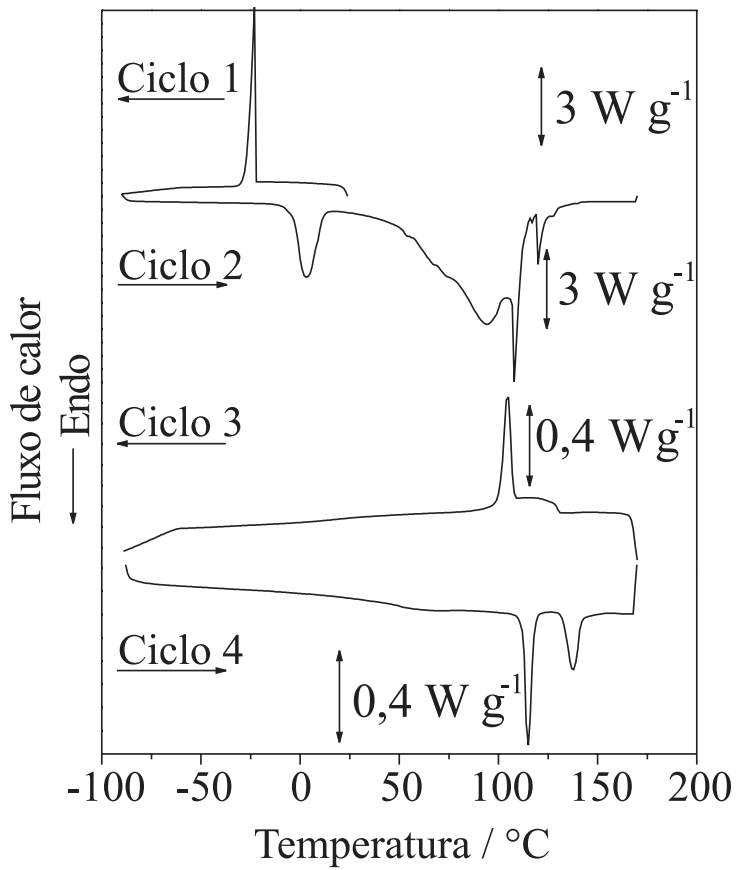

Figura 4S. Curva DSC do Napal, realizada em ciclos de aquecimento/resfriamento entre -90 e $170{ }^{\circ} \mathrm{C}$ com razão de resfriamento/aquecimento de $10^{\circ} \mathrm{C}$ min ${ }^{-1}$,

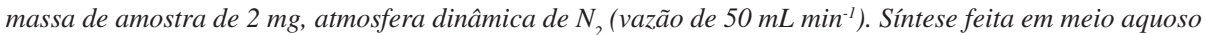

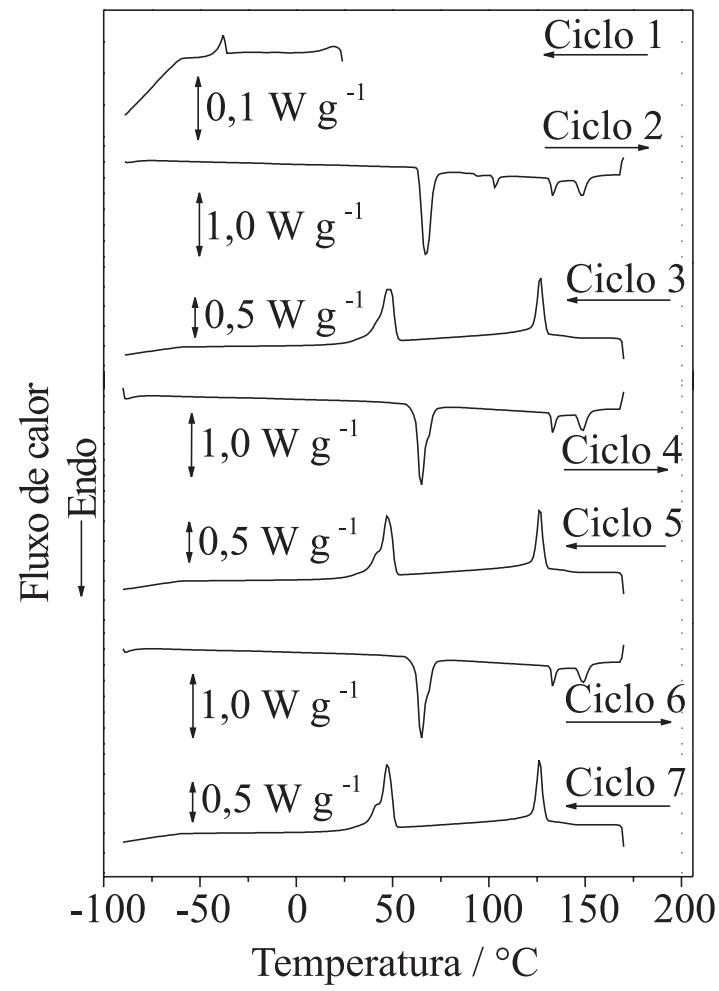

Figura 5S. Curva DSC do Kpal realizada em ciclos de aquecimento/resfriamento entre -90 e $170{ }^{\circ} \mathrm{C}$ com razão de resfriamento/aquecimento de $10{ }^{\circ} \mathrm{C}$ min ${ }^{-1}$, massa de amostra de $2 \mathrm{mg}$, atmosfera dinâmica de $\mathrm{N}_{2}$ (vazão de $50 \mathrm{~mL} \mathrm{~min}^{-1}$ ) 